\title{
Patterns of Ocular Trauma Presenting to the University Hospital of the West Indies in Jamaica \\ JC Nelson-Imoru ${ }^{1}$, L Mowatt ${ }^{1,2}$, CA Walters ${ }^{3}$
}

\begin{abstract}
Objective: The purpose of this study is to identify the causes of ocular trauma, determine the groups at risk and types of injuries presenting to the Eye Unit at the University Hospital of the West Indies.

Method: A prospective observational study was done over a 14-month period on trauma related referrals to the ophthalmology department. A questionnaire was administered and data were collected on the patient's age, gender, affected eye, aetiology and location of trauma, visual acuity and intraocular pressure (IOP). Statistical analysis was performed using STATA.

Results: There were 84 eyes of 80 patients, of which $71.3 \%$ were males and $28.7 \%$ were females. The ages ranged from 3-64 (mean $31.2 \pm 15.1$ ) years. The highest incidence of trauma was seen in the 1835-year age group (41.3\%). Males had an odds ratio risk of 1.37 . Blunt trauma occurred in $35.7 \%$ of cases and penetrating trauma in $33.3 \%$ of cases. The highest incidence of eye injury occurred at home (47.5\%) followed by the workplace (25.0\%), then road traffic setting (13.8\%). Assault-related eye injury was seen in $17.5 \%$ of cases and $62.5 \%$ of all injuries were accidental. The rate of hospitalization was $40.5 \%$, of which $85.3 \%$ were males while $14.7 \%$ were females. Previous trauma in the affected eye occurred in $14.3 \%$ of cases.

Conclusions: Males have a high odds risk ratio of ocular trauma. The majority of eye injuries occur in the home environment. Most injuries were accidental and could be avoided with the use of eye protection or care with interpersonal and work-related activities.
\end{abstract}

Keywords: Blunt trauma, eye injuries, Jamaica, ocular trauma, University Hospital of the West Indies

WIMJ Open 2014; 1 (2): 45

\section{INTRODUCTION}

Ocular trauma is a leading cause of preventable monocular blindness worldwide and is a serious public health concern in developed and developing countries (1). In a research programme for the prevention of blindness, the World Health Organization (WHO) estimated that 55 million eye injuries occur yearly, of which 750000 people require hospitalization (2). There are 2.4 million eye injuries annually in the United States of America [USA] (3). Population based studies in the USA have reported eye injury as the third most common indication for hospitalization in emergency depart-

From: ${ }^{1}$ Ophthalmology Division, Department of Surgery, Radiology, Anaesthesia and Intensive Care, University Hospital of the West Indies, Kingston 7, Jamaica, ${ }^{2}$ Faculty of Medical Sciences, The University of the West Indies, Kingston 7, Jamaica and ${ }^{3}$ Office of the Dean, Faculty of Medical Sciences, The University of the West Indies, Kingston 7, Jamaica

Correspondence: Dr L Mowatt, Ophthalmology Division, Department of Surgery, Radiology, Anaesthesia and Intensive Care, Faculty of Medical Sciences, The University of the West Indies, Kingston 7, Jamaica. E-mail: lizettemowatt@yahoo.com ments, and the National Society for the Prevention of Blindness estimates that up to $90 \%$ of all eye injuries are preventable, especially in the paediatric age group (4-6). Ocular injuries may also be associated with other injuries including facial fractures, in which case severe visual impairment may occur (7).

The impact of ocular trauma is a major cause for concern due to its devastating effects on the individual as well as the burden it places on the socio-economic and health resources of any nation. Epidemiological studies in our environment are necessary to determine the causes of ocular trauma so that strategies to prevent or reduce their occurrence are implemented. This study was conducted to identify the aetiology and nature of ocular trauma affecting our population, including the groups at risk, visual outcome and the need for hospitalization or surgery in our setting.

\section{SUBJECTS AND METHODS}

This is a prospective study of 80 patients referred to the ophthalmology division of the University Hospital of the 
West Indies (UHWI) during a 14-month period. Consecutive subjects who were referred to the eye unit with eye injury were invited to participate in the study and were included once written consent was obtained.

Data were collected on patient's age, gender, affected eye, aetiology of trauma, place of trauma, use of eye protection, imaging studies done, surgical intervention, visual acuity and intraocular pressure (IOP) at presentation, at three months and length of follow-up. Additional ocular and nonocular injuries, the need for combined sub-specialty management and additional ocular imaging were recorded. The study was approved by the University Hospital of the West Indies/University of the West Indies/Faculty of Medical Sciences Ethics Committee. Confidentiality and anonymity were maintained and the study was conducted according to the guidelines of the Declaration of Helsinki. Results were analysed using statistical analysis from STATA 12.0 software and correlations using various statistical methods were reported.

\section{RESULTS}

A total of 84 eyes of 80 consecutive subjects comprised this study.

\section{Age and gender distribution}

The study group included 57/80 (71.3\%) males and 23/80 (28.7\%) females, with $>2.5: 1$ ratio of male to female incidence of eye injury. The ages ranged from 3-64 (mean 31.7 \pm 15.1 ) years. The females ranged in age from 3-56 (mean $29.4 \pm 16.2$ ) years, while the males ranged in age from 9-64 (mean $32.6 \pm 14.8$ ) years. The subjects were categorized into three age groups: $<18$ years old $(21.4 \%), 18-35$ years old $(38.1 \%)$ and $>35$ years old $(40.5 \%)$. On further analysis, no significant differences in association was found between age group and gender (Chi-squared 0.451, $p=0.502$ ). Males experienced more ocular trauma than females in all age groups except in the $<18$-year old group (Fig. 1).

The risk ratio of males developing ocular trauma compared to females was $1.32(95 \%$ CI $0.37,4.78, p=$ 0.669 ). Adults in the age group $18-35$ years had an odds ratio of $1.35(p=0.700)$ for developing ocular trauma when compared to those $<18$ years old, and the $>35$-year age group had an odds ratio of $1.23[p=0.793]$ (Table 1 ).

\section{Aetiological agents of eye injury}

The majority (21.4\%) of injuries were caused by blunt objects (Fig. 2). These were of various sizes and materials

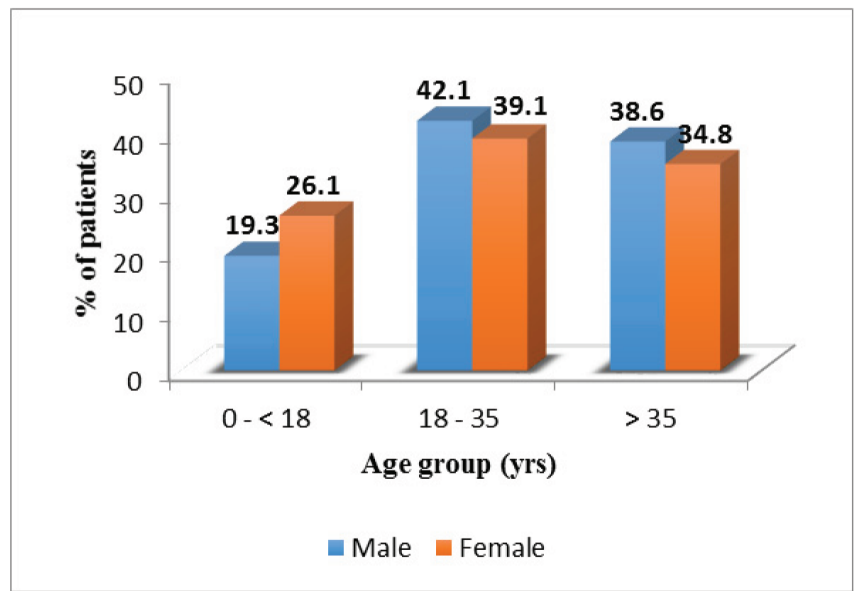

Fig. 1: Age and gender distribution of the sample population.

including plastic bottles, a mobile phone, stones and a belt buckle. Road traffic accidents caused $13.1 \%$ of injuries which resulted from broken side mirrors and windscreens (Fig. 2). Vegetative and plant matter such as sticks, wood and

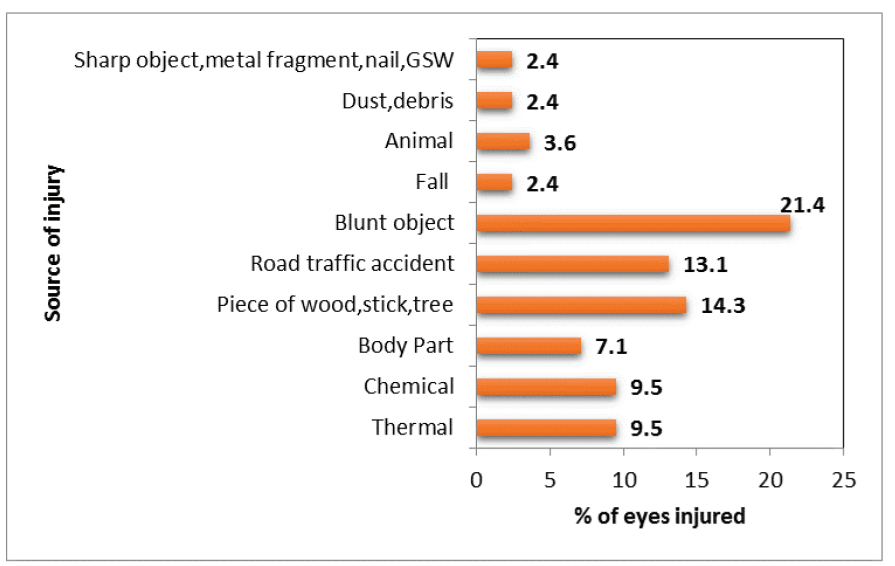

Fig. 2: Aetiological agents causing eye injury.

GSW: gunshot wound

tree branches resulted in $12(14.3 \%)$ eye injuries. There was a similar incidence of chemical and thermal aetiological agents causing injury $(9.5 \%$ each). Two patients sustained bilateral thermal injury after a microwaved egg exploded. Chemical injuries were caused by battery acid, household bleach and cement in its powdered or mixed forms. There was one incidence of injury due to a gunshot wound.

Table 1: Logistic regressions adjusted for age and gender

\begin{tabular}{lcccc}
\hline Characteristics & $\begin{array}{c}\text { Number of eyes } \\
\mathbf{n}(\%)\end{array}$ & Odds ratio & $\begin{array}{c}\mathbf{9 5 \%} \text { confidence } \\
\text { interval }\end{array}$ & p-value \\
\hline $\begin{array}{l}\text { Gender, male } \\
\text { Age (years) }\end{array}$ & & 1.32 & $(0.37,4.78)$ & 0.669 \\
$\quad$ Paediatrics $(<18)$ & $18(21.4 \%)$ & 1.00 & - & - \\
$18-35$ & $32(38.1 \%)$ & 1.35 & $(0.29,6.20)$ & 0.700 \\
Over 35 & $34(40.5 \%)$ & 1.23 & $(1.25,5.97)$ & 0.793 \\
\hline
\end{tabular}


Injuries related to road traffic accidents accounted for a significant proportion of eye injuries and all age groups were susceptible; $13.75 \%$ of ocular injuries sustained occurred from road traffic accidents (Fig. 3). Seatbelts were not used

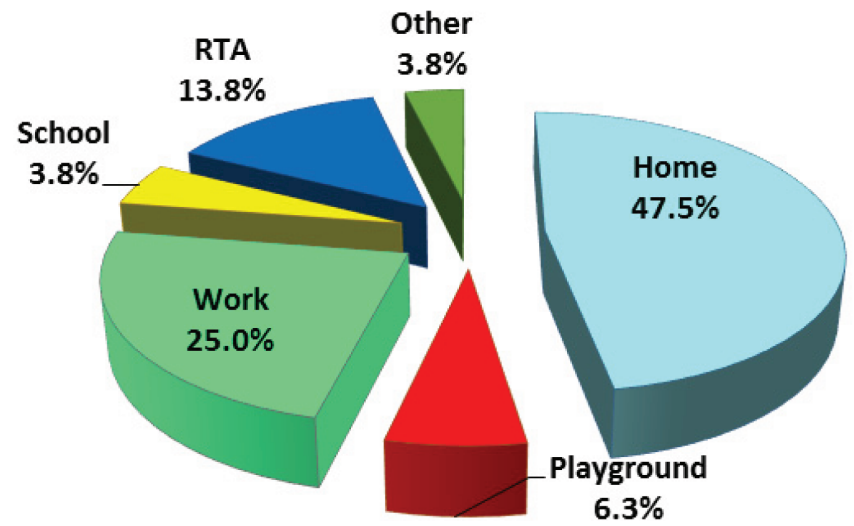

Fig. 3: Location of where the ocular injury occurred. RTA: road traffic accident

in $72.7 \%$ of the road traffic accidents. They were only used in three out of 11 road traffic accident-related cases (Table 2). Road traffic accidents were more frequent in males than females with an almost 1.75:1 ratio and resulted in penetrating injuries in $81.8 \%$ of cases, with the exception of only two students $<18$ years old. However, the 18-35-year age group was most affected in the road accident setting

Table 2: Characteristics of eye injury in 84 eyes of 80 patients

\begin{tabular}{|c|c|c|c|}
\hline Gender & $0-<18$ years & 18 - 35 years & $>35$ years \\
\hline Male, n (\%) & $11(64.7)$ & $24(72.7)$ & $22(73.3)$ \\
\hline Female, n $(\%)$ & $6(35.3)$ & $9(27.3)$ & $8(26.7)$ \\
\hline \multicolumn{4}{|l|}{ Location of injury } \\
\hline Home, n (\%) & $10(58.8)$ & $11(33.3)$ & $17(56.7)$ \\
\hline Playground, n (\%) & $3(17.7)$ & $1(3.0)$ & $1(3.3)$ \\
\hline School, n (\%) & $1(5.9)$ & $2(6.1)$ & $0(0)$ \\
\hline Work, n (\%) & $1(5.9)$ & $8(24.2)$ & $11(36.7)$ \\
\hline Road traffic accident, $\mathrm{n}(\%)$ & $2(11.8)$ & $8(24.2)$ & $1(3.3)$ \\
\hline Other, n (\%) & $0(-)$ & $3(9.1)$ & $0(0)$ \\
\hline \multicolumn{4}{|l|}{ Intent of injury } \\
\hline Assault, n (\%) & $4(23.5)$ & $5(15.1)$ & $5(16.7)$ \\
\hline Accidental, n (\%) & $13(76.5)$ & $22(66.7)$ & $15(50.0)$ \\
\hline Self-inflicted, n (\%) & $0(-)$ & $6(18.2)$ & $10(33.3)$ \\
\hline \multicolumn{4}{|l|}{ Eye protection } \\
\hline Not required, n (\%) & $16(94.1)$ & $22(66.7)$ & $19(63.3)$ \\
\hline Required, n (\%) & $1 \quad(5.9)$ & $11(33.3)$ & $11(36.7)$ \\
\hline \multicolumn{4}{|l|}{ Seatbelt } \\
\hline Not required and not used, $\mathrm{n}(\%)$ & $15(88.2)$ & $24(72.7)$ & $30(100.0)$ \\
\hline Required and not used, n (\%) & $1 \quad(5.9)$ & $7 \quad(21.2)$ & - \\
\hline Required and used, $\mathrm{n}(\%)$ & $1(5.9)$ & $2(6.1)$ & - \\
\hline \multicolumn{4}{|l|}{ Hospitalization } \\
\hline Yes, n $(\%)$ & $8(47.1)$ & $13(39.4)$ & $8(26.7)$ \\
\hline No, $\mathrm{n}(\%)$ & $9(52.9)$ & $20(60.6)$ & $22(73.3)$ \\
\hline
\end{tabular}

( $24.2 \%)$, where only $27.3 \%$ of passengers had the required seatbelts in use.

\section{Location of injury}

The highest incidence of eye injury occurred at home $(47.5 \%)$, followed by the workplace $(25.0 \%)$; eye injury related to road traffic accidents accounted for $13.8 \%$ (Fig. 3). Blunt trauma $(18 / 38 ; 47.3 \%)$ was the cause of most injuries occurring at home, while penetrating injuries occurred in $31.6 \%$ [12/38] (Fig. 4). Thermal and chemical corneal burns

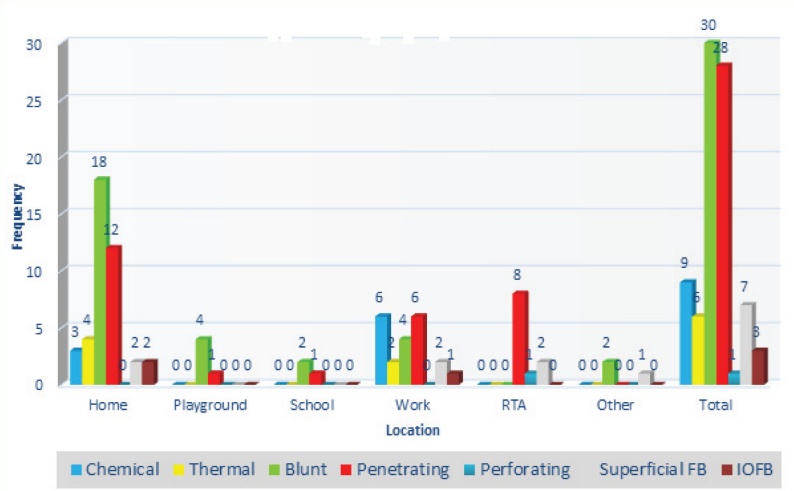

Fig. 4: Distribution of injury by location and type.

RTA: road traffic accident; IOFB: intraocular foreign body

also occurred at home. There were two cases of intraocular foreign bodies (IOFB) at home in which eye protection was not used whilst hammering nails.

Males $(23 / 38 ; 60.5 \%)$ were more likely to suffer ocular injuries at home than females $(15 / 38 ; 39.4 \%)$. The use of eye protection was required at home in 10 cases $(26.3 \%)$ and at work in 12 cases $(63.2 \%)$, but was not used. More than half of the population $>35$ years old $(56.7 \%)$ and $<18$ years old $(58.8 \%)$ suffered eye injury at home, followed by $33.3 \%$ in the 18-35-year age group (Table 2).

\section{Type of injury}

Eye injuries included blunt trauma $(30 / 84 ; 35.7 \%)$, penetrating injury $(28 / 84 ; 33.3 \%)$, corneal burns (thermal burns $(6 / 84 ; 7.1 \%)$ and chemical burns $(9 / 84 ; 10.7 \%))$, perforating injury $(1 / 84 ; 1.2 \%)$ and intraocular foreign body (IOFB) in $3.6 \%(3 / 84)$ of cases (Fig. 5). There was one anterior segment IOFB (in the lens) and two posterior segment IOFB (within vitreal cavity), and seven non-penetrating superficial foreign bodies (7/84) in $8.3 \%$ of cases. Males were more likely to sustain a penetrating than blunt injury when compared to females, risk ratio of 1.12 .

\section{Type of injury and intraocular pressure}

Blunt trauma was the most common injury, occurring in $35.7 \%$ of cases, whilst penetrating injury occurred in $33.3 \%$ of cases (Fig. 5). The mean intraocular pressure (IOP) at presentation was $15.5 \pm 6.7 \mathrm{mmHg}$ (range $7-42 \mathrm{mmHg}$ ). 


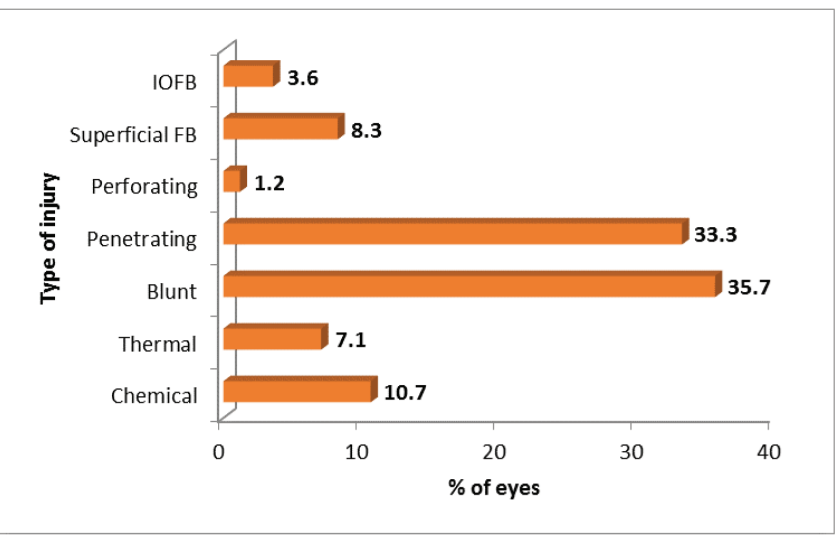

Fig. 5: Type of injury.

IOFB: intraocular foreign body; FB: foreign body

Three injured eyes had elevated IOP on presentation with values of 35,38 and $42 \mathrm{mmHg}$, all resulting from blunt trauma. Of these, two were hospitalized and required surgical intervention. Blunt trauma showed a higher incidence of elevated IOP, $13.3 \%$ versus $3.6 \%$ (penetrating). Patients suffering from blunt trauma eye injuries were more likely to present with visual acuity of count fingers or worse due to hyphaema formation. The mean IOP on discharge was 13.7 \pm 6.2 (range $2-35$ ) $\mathrm{mmHg}$.

\section{Visual acuity}

The mean LogMAR visual acuity on presentation in the affected eye was $1.05 \pm 1.15$. The mean visual acuity on discharge was $0.74 \pm 1.09$. Younger patients were more likely to have better visual acuities on discharge. In the $<18$ year age group, the mean LogMAR vision on discharge was $0.66 \pm 1.06$ compared to $0.75 \pm 1.10$ in adults.

\section{Intent of injury}

Assault-related eye injury was seen in $17.5 \%$, accidental in $62.5 \%$ and self-inflicted in $20 \%$ of cases (Fig. 6).

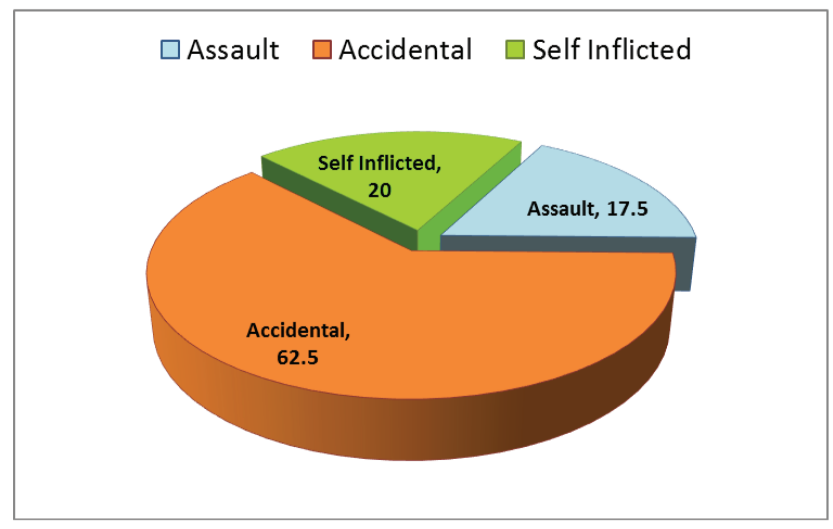

Fig. 6: Percentage of patients according to intent of eye injury.
Incidence of hospitalization associated with type of injury The incidence of hospitalization for ocular trauma was $40.5 \%$ and this was associated with penetrating (58.8\%), blunt (17.6\%), thermal (11.8\%), and perforating (8.8\%) injuries. Males were hospitalized in $34.5 \%$ of cases and female admissions were $14.7 \%$. Younger patients were more likely to have an injury requiring admission. Hospitalization was most common in the $<18$-year age group (47.1\%), than the 18-35 years age group (39.4\%) and those $>35$ years old [26.7\%] (Table 2). Males were more likely to be admitted than females, in a 4:1 ratio.

Surgical intervention was required in $45.2 \%$ (38/84) of eye injuries compared to $54.8 \%(46 / 38)$ of cases which were treated conservatively. Additional ocular injury was observed in nine of 84 cases. Additional imaging was required in 27 cases $(32.14 \%)$ and the most frequent single imaging studies utilized were X-ray imaging (15.5\%), B scan ultrasound $(7.1 \%)$ and computed tomography (CT) scan in 3.6\% of cases. Combined imaging (two or more) was utilized in $5.6 \%$ of cases.

\section{Previous vision and trauma in affected and fellow eye}

Abnormal vision in the affected eye before presentation was reported in $10.7 \%$ of subjects and previous trauma to the affected eye was $14.3 \%$ (12 of 84 eyes). Regarding the fellow eye, only $3.4 \%$ of patients had sustained previous eye injury.

\section{DISCUSSION}

Ocular trauma has been investigated in many populationbased studies in the USA and Canada as well as the United Kingdom and Australia (8-12). There is a geographical variation in the cause of ocular injury which is age and gender specific $(8,9,13-15)$. Studies from different regions (4) such as the Caribbean $(8,9)$ Singapore (13) and India (14, 15) demonstrate variations in the characteristics, incidence and prevalence of ocular trauma. These variations emphasize the influence of different methods of data collection, socioeconomic factors and industrialization of a population on the epidemiology of eye trauma.

Another factor worth considering is the inclusion criteria used in any given study to define ocular trauma. In our study, this was interpreted as any injury to the eye and adnexa which led to an emergency ophthalmology referral. Other definitions include: injuries which result in the restriction of an individuals' normal activities for at least one day, injuries which result in, or threaten permanent visual loss and structural changes, or a recent injury which causes a patient to seek medical attention $(16,17)$.

Some methods used in the literature for data collection include surveys via telephone interviews $(17,18)$, the review of emergency department records (10) and hospital discharge statistics $(13,19,20)$, each of which has advantages and 
disadvantages. In this study, we utilized patient interviews similar to the method described in one study by Khatry et al (16). Such methods tend to be more accurate than data from emergency departments which tend to be biased toward much more severe injuries. Also, discharge data information is dependent on the specific coding utilized for the patient's injury which is limited in cases of multiple trauma to fewer (one or two) diagnoses (16).

The present study demonstrates that Jamaican males are more susceptible to eye injury than females, irrespective of their age. There was a male predominance with a male:female ratio of 2.5:1 which is similar to earlier studies $(8,9)$. This was comparable to other studies varying between 1.74 and $5.5(4,6,11,16,17,21)$. The highest incidence of ocular trauma occurred in the 18-35-year age group. This concurs with other studies but some authors also describe a bimodal pattern where an increased incidence is observed in the 25-30-year age group (first peak), and the second peak incidence is seen after 70 years $(13,19)$.

Blunt injuries were the most frequent type of injury and resulted in severe ocular injuries such as hyphaema, ruptured or dislocated lens, vitreous haemorrhage, secondary glaucoma and rhegmatogenous retinal detachment. This was different from an earlier study where $50 \%$ of ocular injuries were open globe and $29.8 \%$ were from blunt trauma in hospitalized adults with ocular injuries (8). In the present study, one patient presented with a retinal detachment and had a final visual outcome of no perception of light. Blunt trauma showed a higher incidence of elevated IOP, $13.3 \%$ versus $3.6 \%$, when compared to penetrating trauma, and cases with blunt trauma were more likely to present with severe visual impairment (visual acuity worse than counting fingers). There was a high association between blunt trauma and the need for hospitalization.

Hyphaema as a result of ocular injury can be a concern due to the presence of the sickle cell gene in $10 \%$ of the Jamaican population (22). Mowatt and Chambers previously reported that $45.4 \%$ of Jamaican patients presenting with hyphaema had elevated IOP > $21 \mathrm{mmHg}$; of these, $18 \%$ had the sickle cell trait (23). This condition makes them more prone to glaucoma due to the sickling of the red blood cells, which blocks the trabecular meshwork. Further, the use of carbonic anhydrase inhibitors is contraindicated due to the risk of precipitating a sickling crisis. Of the sickle cell patients in that study, $80 \%$ had elevated IOPs of between 29 and $64 \mathrm{mmHg}$ on presentation (23). Management for these cases can be difficult and may result in surgical intervention to control the glaucoma. In the present study, we did not collect data on sickle cell status.

The highest incidence of ocular trauma in Jamaica occurs at home followed by the work place, then road traffic accidents. The domestic setting produced all types of trauma, but blunt and penetrating injuries were the most frequent types of injuries occurring in the home. This correlation was also seen in studies by Desai et al and Khatry et al $(11,16)$.
In the paediatric age group, our study reports and agrees with the literature that the majority of injuries occurred at home and could be avoided with supervision (4, 8, 9, 24). These important trends highlight the need for prevention strategies to increase public awareness and re-emphasize the use of protective eyewear within the high-risk groups in the population while engaging in common domestic activities which can likely cause eye injury. These trends also indicate that further efforts are still required in our population to regulate the availability and use of effective eye protection in the workplace setting. Stricter penalties for non-compliance should be enforced to ensure good practices amongst workers. Estimations by Dannenberg et al suggest that less than $10 \%$ of injured workers used adequate protective eyewear at the time of injury (25).

Penetrating injuries are also a significant public health problem, frequently caused by sharp objects, metal fragments, pieces of wood and glass fragments. In other studies, metallic and sharp objects were more frequently the cause of eye injuries in males, while females showed a higher risk of blunt trauma $(21,26)$. In the present study, $33.3 \%$ of patients had penetrating injury compared with $1.9-9.2 \%$ in other studies $(11,12,16,27)$.

These findings may be attributed to less strict seatbelt enforcement laws in our environment. Also, this study was conducted in the capital city of Kingston where students and the majority of the adult workforce (18-35-year age group) commute daily from the rural areas via public and private transportation and they are equally susceptible to injury. The use of seatbelts has been shown to prevent ocular injuries and reduce the risk of mortality. In developed countries, legislation along with close surveillance via closed circuit systems encourages this practice $(28,29)$. In our environment, stricter enforcement regulations will decrease the incidence of severe ocular trauma in all age groups.

Ocular trauma related to assault was reported between 9.2 and $16.3 \%$ in the literature reviewed and, similar to our study, was mostly associated with body parts and blunt objects $(6,27)$. In our paediatric group, injury was seen in the domestic and road traffic setting. Suggestions for ways to improve and resolve interpersonal conflicts can reduce the incidence of ocular trauma. Awareness of the causes of ocular trauma and implementation of preventative strategies can help the reduction of serious ocular trauma (30).

Trauma registries have a purpose in collating essential public health information which can be analysed and the results used in planning and policy-making, ultimately reducing morbidity $(3,25,31)$. This would be helpful both for developing countries and also on an international scale with an international trauma databank ultimately allowing countries to have global benchmark data, with the aim of improving our trauma care systems and prevention policies (32).

The majority of eye injuries in Jamaica occur at home and are preventative. Public education campaigns must be 
aimed at the groups at risk identified in this study as they form the majority of the working population and are directly related to the productivity and socio-economic growth of the island. A reduction in ocular trauma will reduce permanent visual impairment, leading to a significant reduction in the burden on the health services of the island.

\section{ACKNOWLEDGEMENTS}

Thanks to the resident staff at the eye department of the University Hospital of the West Indies for assistance with administration of the questionnaires for the study.

\section{Author contributions}

Study design and questionnaire: LM; collection of data: JNI; analysis of data: JNI, LM; statistical analysis and construction of tables: JNI, CAW, LM; wrote paper: JNI, LM.

\section{REFERENCES}

1. May DR, Kuhn FP, Morris RE, Witherspoon CD, Danis RP, Matthews GP et al. The epidemiology of serious eye injuries from the United States Eye Injury Registry. Graefes Arch Clin Exp Ophthalmol 2000; 238: $153-7$.

2. Négrel AD, Thylefors B. The global impact of eye injuries. Ophthalmic Epidemiol 1998; 5: 143-69.

3. US Eye Injury Registry. Epidemiology: scope of the problem [Internet]. [cited 2014 Feb 8]. Available from: http://www.useironline.org/ epidemiology

4. Abbott J, Shah P. The epidemiology and etiology of pediatric ocular trauma. Surv Ophthalmol 2013; 58: 476-85.

5. Pollard KA, Xiang H, Smith GA. Pediatric eye injuries treated in US emergency departments, 1990-2009. Clin Pediatr (Phila) 2012; 51: 374-81.

6. Cao H, Li L, Zhang M. Epidemiology of patients hospitalized for ocular trauma in the Chaoshan region of China, 2001-2010. PLoS One 2012; 7: e48377.

7. Magarakis M, Mundinger GS, Kelamis JA, Dorafshar AH, Bojovic B, Rodriguez ED. Ocular injury, visual impairment, and blindness associated with facial fractures: a systematic literature review. Plast Reconstr Surg 2012: 129: 227-33.

8. Mowatt L, McDonald A, Ferron-Boothe D. Hospitalization trends in adult ocular trauma at the University Hospital of the West Indies. West Indian Med J 2012; 61: 605-9.

9. Mowatt L, McDonald A, Ferron-Boothe D. Paediatric ocular trauma admissions to the University Hospital of the West Indies 20002005. West Indian Med J 2012; 61: 598-604.

10. Karlson TA, Klein BE. The incidence of acute hospital-treated eye injuries. Arch Ophthalmol 1986; 104: 1473-6.

11. Desai P, MacEwen CJ, Baines P, Minassian DC. Epidemiology and implications of ocular trauma admitted to hospital in Scotland. J Epidemiol Community Health 1996; 50: 436-41.

12. McCarty CA, Fu CL, Taylor HR. Epidemiology of ocular trauma in Australia. Ophthalmology 1999; 106: 1847-52.

13. Wong TY, Tielsch JM. A population-based study on the incidence of severe ocular trauma in Singapore. Am J Ophthalmol 1999; 128: $345-$ 51.
14. Krishnaiah S, Nirmalan PK, Shamanna BR, Srinivas M, Rao GN, Thomas R. Ocular trauma in a rural population of southern India: the Andhra Pradesh Eye Disease Study. Ophthalmology 2006; 113: 115964.

15. Nirmalan PK, Katz J, Tielsch JM, Robin AL, Thulasiraj RD, Krishnadas $\mathrm{R}$ et al. Ocular trauma in a rural south Indian population: the Aravind Comprehensive Eye Survey. Ophthalmology 2004; 111: 1778-81.

16. Khatry SK, Lewis AE, Schein OD, Thapa MD, Pradhan EK, Katz J. The epidemiology of ocular trauma in rural Nepal. Br J Ophthalmol 2004; 88: 456-60.

17. Glynn RJ, Seddon JM, Berlin BM. The incidence of eye injuries in New England adults. Arch Ophthalmol 1988; 106: 785-9.

18. Gordon KD. The incidence of eye injuries in Canada. Can J Ophthalmol 2012; 47: 351-3

19. Tielsch JM, Parver L, Shankar B. Time trends in the incidence of hospitalized ocular trauma. Arch Ophthalmol 1989; 107: 519-23.

20. Klopfer J, Tielsch JM, Vitale S, See LC, Canner JK. Ocular trauma in the United States. Eye injuries resulting in hospitalization, 1984 through 1987. Arch Ophthalmol 1992; 110: 838-42.

21. Soylu M, Sizmaz S, Cayli S. Eye injury (ocular trauma) in southern Turkey: epidemiology, ocular survival, and visual outcome. Int Ophthalmol 2010; 30: 143-8.

22. Downes SM, Hambleton IR, Chuang EL, Lois N, Serjeant GR, Bird AC. Incidence and natural history of proliferative sickle cell retinopathy: observations from a cohort study. Ophthalmology 2005; 112: 1869-75.

23. Mowatt L, Chambers C. Ocular morbidity of traumatic hyphema in a Jamaican hospital. Eur J Ophthalmol 2010; 20: 584-9.

24. Chen AJ, Linakis JG, Mello MJ, Greenberg PB. Epidemiology of infant ocular and periocular injuries from consumer products in the United States, 2001-2008. J AAPOS 2013; 17: 239-42.

25. Dannenberg AL, Parver LM, Brechner RJ, Khoo L. Penetrating eye injuries in the workplace. The National Eye Trauma System Registry. Arch Ophthalmol 1992; 110: 843-8.

26. Wong TY, Klein BE, Klein R. The prevalence and 5-year incidence of ocular trauma. The Beaver Dam Eye Study. Ophthalmology 2000; 107: 2196-202.

27. Pandita A, Merriman M. Ocular trauma epidemiology: 10-year retrospective study. N Z Med J 2012; 125: 61-9.

28. Hall NF, Denning AM, Elkington AR, Cooper PJ. The eye and the seatbelt in Wessex. Br J Ophthalmol 1985; 69: 317-19.

29. Pace BW, Thailer R, Kwiatkowski TG. New York State mandatory seatbelt use law: patterns of seatbelt use before and after legislation. $\mathrm{J}$ Trauma 1986; 26: 1031-3.

30. Morris DS, Willis S, Minassian D, Foot B, Desai P, MacEwen CJ. The incidence of serious eye injury in Scotland: a prospective study. Eye (Lond) 2014; 28: 34-40.

31. Nwomeh BC, Lowell W, Kable R, Haley K, Ameh EA. History and development of trauma registry: lessons from developed to developing countries. World J Emerg Surg 2006 [cited 2014 Mar 23]; 1: 32. doi: 10.1186/1749-7922-1-32. Available from: http://www.ncbi.nlm. nih.gov/pmc/articles/PMC1635421/pdf/1749-7922-1-32.pdf

32. Haider A. Playing darts without a dart board: why we need to create an International Trauma Data Bank (ITDB). Injury 2014; 45: 1-2.

Submitted 09 Apr 2014

Accepted 23 Apr 2014

Published 17 Jun 2014

Online: http://myspot.mona.uwi.edu/wimjopen/article/70

(C) Nelson-Imoru et al 2014.

This is an open access article made freely available under Creative Commons Attribution 4.0 International (CC BY 4.0). Users are free to share, copy and adapt this work as long as the copyright holder (author) is appropriately and correctly credited. See http://creativecommons. org/licences/by/4.0/deed.en_us for more information. 